\title{
Exporting Online Engineering Management Programs: Enablers, Barriers, and Descriptions of Programs at Two Universities
}

\section{Dr. Luna Magpili, Washington State University}

Luna Magpili is an Associate Professor of Engineering and Technology Management at Washington State University and has been involved in academic teaching and research for more than 10 years. She has had extensive international experience as an industrial engineer and consultant for various manufacturing and export enterprises and have collaborated with Philippines universities in her research endeavors. She currently serves as panel reviewer to various programs at NSF, NASA, and DoD. She also serves as referee to various journals such as Risk Analysis, Environmental Science and Technology, and Environmental Monitoring and Assessment. She is a member of INCOSE, ASEM, ASEE, IISE and TOCICO. She has been named Top 20 Professors in Engineering Technology To Know, OnineEngineeringPrograms.com.

\section{Dr. Alice F. Squires, Washington State University}

Dr. Alice F. Squires has served in technical and leadership roles for over 35 years. After nearly 25 years in industry, Alice is serving engineering education as an Associate Professor in the Engineering and Technology Management department of Washington State University. Alice is Founder of the INCOSE Empowering Women as Leaders in Systems Engineering (EWLSE) committee and serves in leadership positions for INCOSE Academic Matters, and the ASEE Systems Engineering Division, Corporate Member Council, and Committee on Diversity, Equity, and Inclusion. She recently completed an autobiographical book to be published by IEEE Women in Engineering (WIE) in May 2019 as an ebook in a series on women overcoming various challenges to complete a STEM education and succeed as an engineering professional, titled: "Dandelion Wishes: A World Where We Collaborate as Equals".

\section{Dr. Kim Bullington Sibson, Old Dominion University}

Dr. Sibson is an experienced and accomplished leader in higher education and university administration with strong expertise in program management, organizational development, and student and academic affairs administration, with over two decades of university experience.

During this time, Dr. Sibson has worked on numerous projects and initiatives aimed at forging strategic relationships and building consensus among faculty, staff, and students while being a motivated self-starter and reliable colleague. Seeking opportunities to expand her knowledge in her many areas of expertise, Dr. Sibson will bring her unique approach to higher education administration to ensure student success.

\section{Dr. Linda Vahala, Old Dominion University}

Dr. Linda Vahala received her B.S..degree from the University of Illinois in 1969, an M.S. degree from the University of Iowa in 1971, and a Ph.D from Old Dominion University in 1983. Her publications include articles in both plasma physics and atomic physics with an emphasis on laser interactions with plasma and with neutral/rare gas collisions. She has presented her work at various international workshops and meetings, both in Europe and in the United States. She is currently Associate Professor in Electrical and Computer Engineering. In 1995, she received the Peninsula Engineer of the Year award.

\section{Aysen K. Taylor, Old Dominion University}

Aysen K. Taylor is a Ph.D. candidate at Old Dominion University in the Engineering Management and Systems Engineering department. She received her Bachelor degree from Istanbul Technical University Textile Engineering in the Mechanical Engineering department. Following this, she earned her degree of Masters of Science in Industrial Engineering from Istanbul Technical University. After working in the industry for ten years in several pioneering companies as manager and project leader, she received her Masters of Engineering Management degree from Old Dominion University. Her research interests include human-machine interaction, machine learning, decision making in complex environments, naturalistic decision making and cockpit automation. 


\title{
Exporting Online Engineering Management Programs: Enablers, Barriers, and Examples from Two Universities
}

\begin{abstract}
This paper investigates enablers and barriers for Engineering Management Degree Granting Programs offered online by universities located in the United States to students located in foreign countries. Using a strong foundation of literature research and two universities on opposite sides of the country (one east coast, one west coast) exporting online Engineering Management programs as examples, the paper investigates seven enablers and seven barriers. The enablers and barriers are reviewed in the context of delivering engineering management education online across national borders, without requiring students to travel to another country (referred to as Mode 1 service export). The investigation reveals two main findings: 1) that factors of success are driven by a function of the students, the host countries, the offering institutions and the competitive climate at any time, and 2) that Mode 1 service export of Engineering Management programs results in benefits to the universities offering such programs and the students taking the programs.
\end{abstract}

\section{Introduction}

Fueled by globalization, productivity and innovation are increasingly dependent on the continual development of human capital through such means as higher education. In 2016, more than 4.8 million students studied outside their country of residence, which is more than double the number in 2000 [1]. This growing demand for higher education worldwide gives rise to higher education that is also becoming increasingly global [2]. The landscape for the globalization, or internationalization of education is constantly changing. Students who traditionally would have traveled abroad to study can now choose to pursue foreign degrees in their home, or at local branch institutions nearby. This type of internationalization is known as transnational education (TNE) and is defined by the United Nations Education, Scientific and Cultural Organization (UNESCO) as "all types of higher education study programs, or sets of courses of study, or educational services (including those of distance education) in which the learners are located in a country different from the one where the awarding institution is based"[3]. With the advent of online and distance education and the proliferation of such programs in the United States (U.S.) and other countries, many scholars consider TNE as a logical growth area for online and distance education [4], [5], [6].

According to the General Agreement on Trade in Services (GATS) by the World Trade Organization (WTO), there are four modes of service export [7]. For educational services, these exports are exhibited in the following modes:

1. Mode 1 is cross-border supply where the educational service crosses national boundaries. This includes online learning programs and distance delivery that are delivered through satellites, televisions, computers, Internet, video conference or other technological means. Travel by the consumer of service to another country is not required.

2. Mode 2 is consumption abroad where the consumer of service moves to the country where the awarding institution is located and where the educational service is also provided. This is 
the most common mode where, for example, international students physically travel to the United States to study.

3. Mode 3 is commercial presence where the awarding institution establishes physical presence in other countries other than where it is located. This includes institutions establishing branch or satellite campuses in other countries, franchising, or establishing dual/joint partnership agreements with local institutions. For Mode 3, travel by the consumer to another country is also not required.

4. Mode 4 is the presence of natural persons where people temporarily travel to another country to provide educational service. Examples of this are visiting professor arrangements where engagements are short term and limited, such as a Fulbright grant. The educational service provided may not be student-related but could be research-related or other types of educational collaboration.

Table 1 further differentiates Modes 1-4 depending on where the student, service provided, and awarding institution are located. The Host Country is where the awarding institution is located. The Source Country is the home country where the student is residing and not where the awarding institution is located.

Table 1

MODES 1, 2, 3, 4 OF EDUCATIONAL SERVICE EXPORT

\begin{tabular}{|l|l|l|l|l|}
\hline & Mode 1 & Mode 2 & Mode 3 & Mode 4 \\
\hline $\begin{array}{l}\text { General } \\
\text { Description }\end{array}$ & $\begin{array}{l}\text { Student takes } \\
\text { courses through } \\
\text { distance/ online } \\
\text { learning via } \\
\text { Internet, } \\
\text { computer or } \\
\text { other } \\
\text { technology. }\end{array}$ & $\begin{array}{l}\text { Student takes } \\
\text { classes on } \\
\text { campus by } \\
\text { traveling to } \\
\text { Awarding } \\
\text { Institution's } \\
\text { country location }\end{array}$ & $\begin{array}{l}\text { Student takes } \\
\text { classes in branch } \\
\text { campus located } \\
\text { where the } \\
\text { student resides } \\
\text { but where the } \\
\text { Awarding } \\
\text { institution is not } \\
\text { located. }\end{array}$ & $\begin{array}{l}\text { NA } \\
\text { Service may } \\
\text { not involve } \\
\text { students but } \\
\text { research or } \\
\text { other } \\
\text { collaboration }\end{array}$ \\
\hline $\begin{array}{l}\text { Location of } \\
\text { Student }\end{array}$ & Source Country \\
\hline $\begin{array}{l}\text { Location of the } \\
\text { Service being } \\
\text { Provided } \\
\text { (Professor) }\end{array}$ & Host Country & Host Country & Source Country & NA \\
\hline $\begin{array}{l}\text { Location of } \\
\text { Awarding } \\
\text { Institution } \\
\text { (Provider) }\end{array}$ & Host Country & Host Country & Host Country & Host Country \\
\hline
\end{tabular}

It is worth noting that since the GATS took effect, the U.S. has become the world's largest exporter of higher educational services primarily through Mode 2 (see Figure 1). In 2017, 24\% international students worldwide enrolled and took courses in a U.S. institution, with second place UK at only $11 \%$ [8]. Education was ranked the $6^{\text {th }}$ largest U.S. service export, contributing 
$\$ 43.1$ billion to the U.S. economy [9]. In 2017, the number of international students entering the U.S. topped more than one million for the third consecutive year achieving a new high of $1,094,792$ [10]. However, new student enrollments fell by 6.6 percent in 2017/18 which continues a slowing trend from previous years.

Figure 1

INTERNATIONAL STUDENT ENROLLMENT FOR 2016 IN AUSTRALIA, THE UK, AND THE U.S. BY MODE OF DELIVERY.

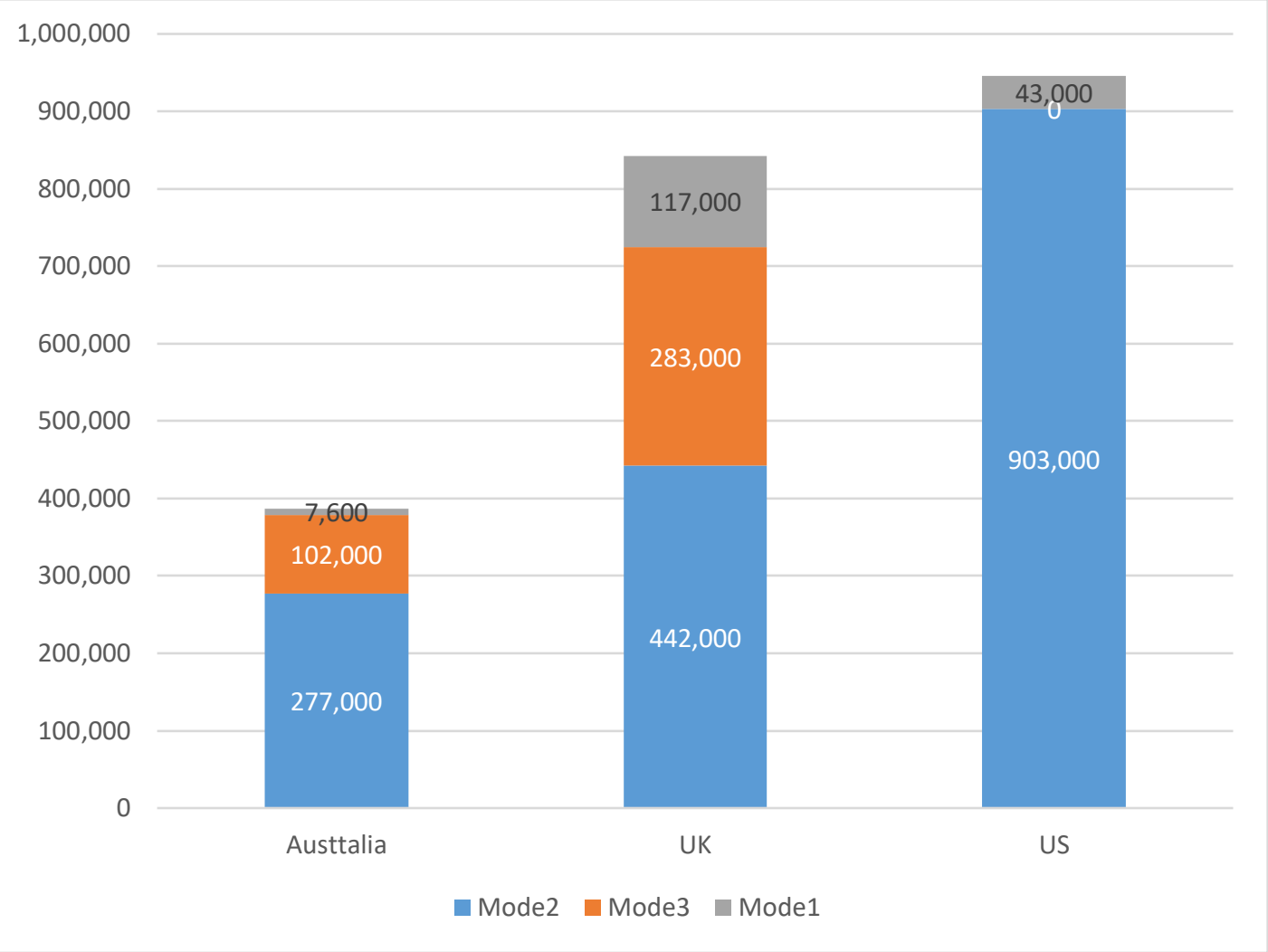

Source: OBHE [11]

While dominating Mode 2, the U.S. has very negligible exports for Mode 3 and relatively few exports via Mode 1. As shown in Figure 1, other countries such as the UK and Australia have extensively used these other modes, and the UK is ahead in Mode 1 according to a report [11] by the Observatory in Borderless Higher Education (OBHE), a UK-based organization. The Babson Survey Group that publishes the annual survey of online education of colleges and universities in the U.S., for the first time, included Mode 1 in its 2018 report. This is perhaps an indication of some trend and interest in measuring such data. According to the Babson report [12], in the Fall of 2016, there were only 45,475 students located outside of the U.S. who were taking exclusively distance courses via Mode 1. Although a slightly different number from the OBHE report $(43,000$ vs 45,475$)$, this represents less than $0.5 \%$ of all international students worldwide.

While relatively a small number, the OBHE reports a 23\% increase from 2009 for Mode 1 enrollments in the U.S. and it has shown an increasing trend since then (see Figure 2), which is in contrast with the slowing or flattening trend for Mode 2 as reported by the Institute of 
International Education [10], a nonprofit that tracks student mobility in the U.S. Melora [6] adds that online enrollment by U.S. students residing abroad grew at 8.6\%, outpacing domestic online enrollments at only $7 \%$. This seems to indicate that online education may be becoming a more viable choice for students located in foreign countries. Although Garrett [11] cautions against this view, citing the UK's tapering or declining global online enrollments for Mode 1. Note also that the data to date excludes students enrolling in Massive Open Online Courses (MOOCs) or students taking mixed modes (e.g. students taking courses through a combination of Modes 1 and 3). Divergent outlooks, differing enrollment estimates, and data gaps underscore the need for more comprehensive statistics on Mode 1 in order to deepen the understanding of the market, whether there is actual growth and if so, from where it is coming.

Figure 2

Number of StUdents TAKING EXClusively Distance COURSES

LOCATED OUTSIDE OF THE U.S. - 2012-2016

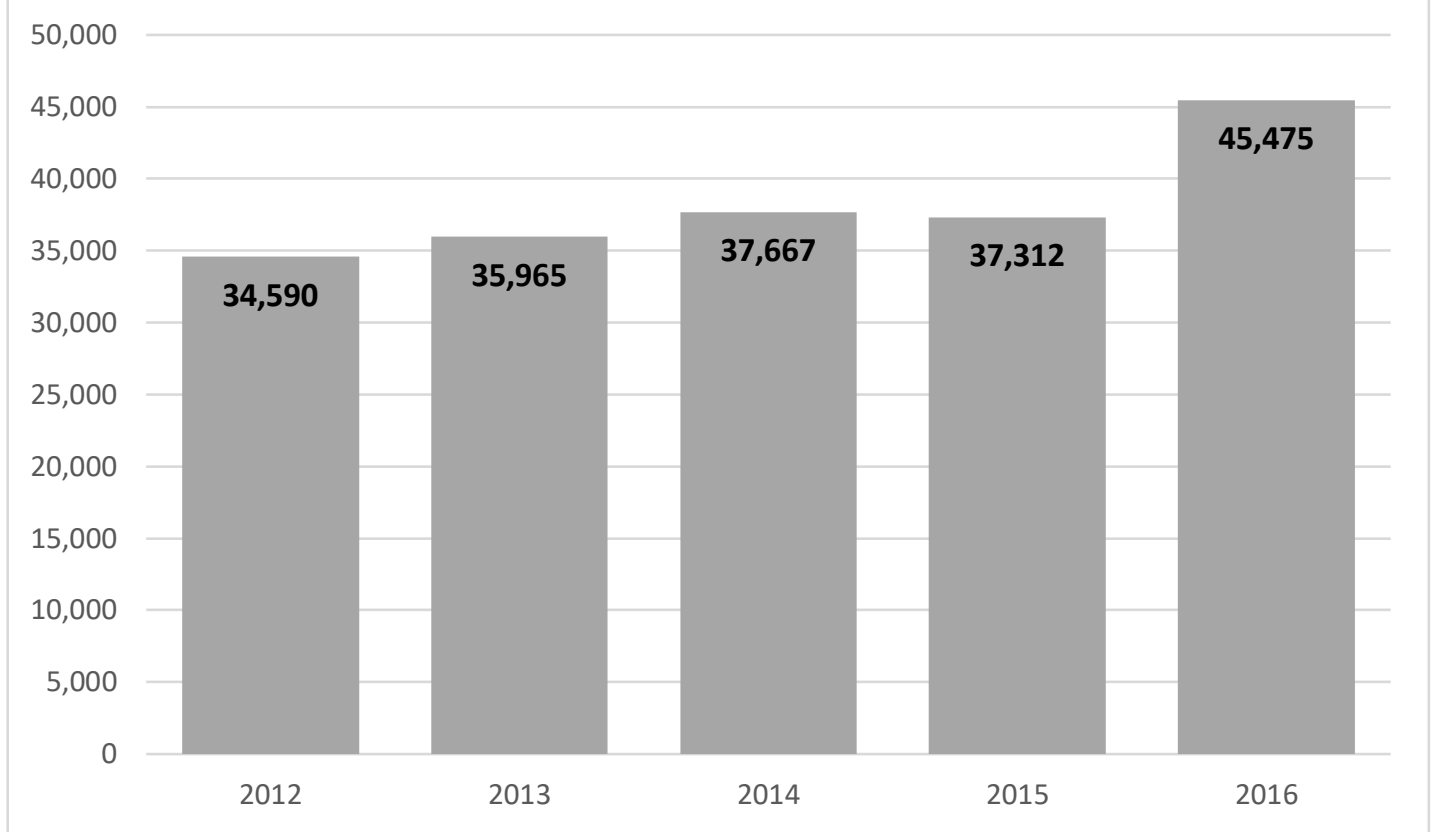

Source: Babson Survey [12]

Given that TNE defines the educational service provided to students be outside of where the awarding institution is based, TNE includes only Modes 1 and 3, and excludes Modes 2 and 4. As a point of clarification, this paper focuses on the subset of TNE that is Mode 1 for online programs in Engineering Management where the awarding institution is located in the U.S. In this case, the international student enrolls in a U.S.-based Engineering Management Degree Program but the student remains in his/her country of residence or any other country other than the U.S. In this case, the U.S. is considered the Host Country and the county where the student is located and residing is the Source Country. Courses are delivered and taken by the student through the Internet and/or other technological means.

To this end, the objective of this paper is to review the enablers and barriers for Engineering Management Degree Granting Programs offered online by universities located in the U.S. to students located in foreign countries. Further, the paper will describe Engineering Management 
Master's Degree Programs offered by two U.S. universities, one on the East Coast, and one on the West Coast. While these two programs currently involve a very small number of students located in foreign countries, their existence suggests that the enablers and barriers for exporting online Engineering Management may align in a manner that could permit growth of this service export with resulting benefits to the universities offering such programs, the students taking the programs, and the U.S. balance of trade.

\section{Literature Review Methodology}

A paper by Knight [13] lays a conceptual map of the different taxonomies, definitions and terms related to TNE. The following table from Knight [13] served as key terms used for the literature search in conjunction with the term "+cross border" or "+online" or "+distance" and "+engineering" or "+engineering management".

Table 2

EVOLUTION OF INTERNATIONAL EDUCATION TERMINOLOGY

\begin{tabular}{|l|l|}
\multicolumn{1}{|c|}{$\begin{array}{c}\text { New Terms } \\
\text { Last 15 years }\end{array}$} & \multicolumn{1}{c|}{$\begin{array}{c}\text { Existing Terms } \\
\text { Last 25 years }\end{array}$} \\
\hline Globalisation/ Globalization & Internationalisation/ Internationalization \\
\hline Borderless education & Multi-cultural education \\
\hline Cross-border education & Inter-cultural education \\
\hline Transnational education & Global education \\
\hline Virtual education & Distance education \\
\hline Internationalization "abroad" or "at home" & Offshore or overseas education \\
\hline
\end{tabular}
Source: Knight [13]

A broad literature search using common academic search engines was used namely, ScienceDirect (http://www.sciencedirect.com/) and Google Scholar (http://scholar.google.com/). A targeted literature search was also performed using search filters for the Journal of Engineering Education, Engineering Management Journal, American Society of Engineering Education conference proceedings (ASEE PEER), American Society for Engineering Management (ASEM) proceedings, the ASEM Journal, and Journal of Studies in International Education.

Searches that used the term "global" or "international education" (and variations thereof) yielded literature that related mostly to Mode 2 students (international students studying in the U.S. or U.S. students traveling abroad to study). The search term, "TNE", produced many results but there were only a few that focused exclusively on online TNE. These papers were mostly authored by international sources and written at a global or country level perspective. Search results with "engineering" and "engineering management" typically covered two primary topics(1) the development and/or efficacy of online EM programs (e.g. development of online community of learners; or online versus traditional face to face learning outcomes for EM), or (2) the enhancement of global engineering competencies through study abroad programs, student exchange and other strategies. Literature that is specific to online TNE in engineering or engineering management was nonexistent. Thus, the discussion in the next two sections is drawn 
from general online TNE literature. The applicability and relevance to engineering management is then discussed in the last section describing the two U.S. universities engaged in TNE Mode 1.

\section{Enablers for Mode 1 Online Programs}

TNE is a market driven activity [14]. Along with economic benefits, several themes have emerged in the literature as enablers to promoting online programs abroad. These themes are: market demand, ease in market entry, consumer preference, online culture, internationalization, emerging visa and immigration policies, and partnerships.

(1) Market demand - The market at the global level is primarily driven by emerging countries that are unable to satisfy national or local demands for higher education. As many institutions cannot expand quickly or adequately enough as a result of capacity and financial constraints, unmet demand for higher education in many developing countries (i.e. source countries) is thus provided by educational services from developed nations (i.e. host countries) [14], [15]. At present, the U.S. has been able to provide this educational service predominantly through Mode2 with India, China and the Middle East as the source of its largest consumers [8]. Thus, in many developed countries, international students have become an important revenue source for many of its institutions [15], [16]. Capturing more of the global market through a variety of modes, and higher tuition fees and cost of attendance for non-U.S. citizens or non-residents has the potential to further increase this economic benefit. According to Altbach and de Wit [17], TNE is currently a billion-dollar industry with universities, private companies, and supporting services such as insurance companies, recruiters, technological support, and other services. Further, entry to online programs can be an attraction, a gateway or a pipeline for international students. Some administrators expect to gain visibility for their institutions by offering online programs (Ward, 2016). Therefore, it can also be a promotional tool to gain access to new markets.

(2) Ease in market entry - The potential for cost savings and the ease of scaling encourages ongoing investments in online education by educational providers. Online programs are generally viewed as a low-cost alternative for delivering education to a greater number of students [15], [18]. That the cost is low from the university's perspective is due to handling a larger number of students at a higher margin per student than on campus [19]. Universities can offer already existing online programs to expand their global presence with relatively less investment, as compared to Modes 3 that requires capital investment and efforts to establish actual physical presence in foreign countries, or Mode 2 that also requires investment to increase classroom space in campuses. While some lesser known schools may have to compete by investing in some marketing and promotion, other well-known institutions may have the benefit of recognition for easier market entry which keeps costs even lower for them.

Moreover, given that online enrollments are becoming a higher proportion of overall enrollments in universities in general, universities particularly in U.S., are also becoming familiar with the challenges of online education and are developing techniques for success in this type of education. These same techniques can be applied directly to TNE Mode 1.

(3) Consumer preference - Many international students struggle to adapt to social and academic life in a new country [20], and these difficulties can impact their academic performance and 
achievement. Culture shock and loneliness have been identified as common problems of international students and can be addressed via Mode 1, where student can remain in their home countries and with their families. Other problems for international students, as identified by Fischbacher-Smith [20] include knowledge gaps, adjustment to teaching styles, and shortcomings in language ability. These may also be addressed by online education playing a different role- as a transitional program to studying in the U.S. An online pipeline of courses can give potential students initial exposure to the U.S. education system. This can be useful not only to assess the fit of the student to the program, but also to successfully transition non-English foreign students to the U.S. system and culture. Bannier [5] has noted this practice with some Chinese students enrolling in online programs of foreign universities in the hopes of eventually earning acceptance and transitioning to on-campus programs at these universities.

Further, Mode 1 provides an opportunity for working professionals to advance and upgrade their credentials while working full time. It allows for pursuing higher education without leaving their home country and existing employment [14]. Liang and Chen [21] points to a "blurring of formal and informal training where on-the-job-training can be enhanced by online resources". Liang and Chen [5] also emphasize the flexibility and availability of content that is directly beneficial to working professionals who are able to afford foreign tuition costs and want to avoid the effort, financial cost, and disruption of moving to another country.

(4) Online culture - The popularity and prevalence of the Internet, social media, smart phones, gaming and online technologies have created a thriving online culture. Liang and Chen [21] even suggests that an online presence over the Internet for many has become more engaging than physical presence and has become a major source of social interaction. The online culture has also increasingly occupied the education space not only in the U.S., but also abroad. Other countries are experiencing a similar change from traditional classrooms to the online environment [5]. More and more students are enrolling in distance and online education, and countries are actively promoting access to them. In China, around $16 \%$ of higher education students were enrolled online, approximately 5.28 million students in 2014 [6]. In the same year, India had 5.42 million distance learning enrollments where the online education market was valued at $\$ 20$ billion with enrollments predicted to grow 10\% in 2019 [6]. However, this online growth in source countries may be viewed also as competition for the Mode 1 market, with demand being met by local supply in the source countries themselves. This is further discussed as a barrier in the paper.

(5) Internationalization - The conventional aspiration of global or international education is promoting multicultural, diverse and global outlooks among students [8], [14], [18], [22]. Further educational value is associated with a diverse student body [8], [18]. This global competency is widely recognized as key to lifelong success. Using online platforms to connect faculty and students beyond national or physical borders is an accessible, affordable, and flexible option for delivering global learning as an alternative to study abroad. Like many study abroad programs, online classroom environments can provide meaningful global learning and cross-cultural experiences [18].

(6) Visa and immigration policies - As stated, many governments in developing countries invest in subsidies and scholarships for their citizens to acquire higher education in developed countries 
as a means to address the lack of capacity of their own education system. However, developed countries are turning to this same pool of talent from which to draw labor. Countries such as Canada, Germany, Japan, and even China have initiated policies that seek to enroll international students, but also retain them in their labor markets. In 2016 for example, Canada adjusted its immigration process to better retain international students in the workforce, by giving additional points to applicants for residency who hold job offers and whose degrees were obtained in the country [8], [23]. Similar policies can be found in Germany [8], [24]. Such labor immigration policies by some host countries may encourage source countries to consider Mode 1 to reduce brain drain and loss of financial investment by their governments. Mode 1 which allows students to stay in their home country may be able to reduce this loss of valuable human capital for source countries.

On one hand is the competition for global talent, and on the other there is the social backlash towards immigrants and foreigners experienced in many host countries. Along with increased competition, regional and local options, and less educational investment from source countries, this negative perception of non-nationals has been identified as one of the factors in the U.S. for a marked rate decrease in international student enrollment [10] [17] [25]. Other factors related to immigration are fear of terrorism, discriminatory policies, and tightening of visa requirements especially from high enrollment source countries such as Saudi Arabia and China [17], [25]. Many U.S. higher education institutions (76\%) expressed concern about future enrollment from the Middle East and the impact on students' willingness or ability to study in the U.S.[8]. Mode 1 can be a viable option to this new norm of restricted mobility.

(7) Institutional Partnership and Collaboration - Guri-Rosenbilt [4] stresses that "successful institutional collaborations of educational providers have the potential to attract new students, reduce costs for course development, enhance flexibility, ensure high quality mechanisms, provide richer and better programs, and strengthen the financial basis" of TNE. Knight [13] and Alam et al. [14] describe forms of partnerships that have been commonly found in many TNE arrangements for Modes 3, and can also be applied to Mode 1.

1. Double/Joint Degree - An arrangement where education providers in different countries collaborate to offer and deliver a program for which a student receives a qualification from each institution or a joint award from the collaborating institutions. Courses can be offered as a combination of online courses from host countries (i.e. a provider from U.S.) and online or face-to-face courses in source countries (i.e. a provider from another country). The student earns either a dual degree or a joint degree from the two provider institutions in both host and source countries.

2. Articulation - Various types of articulation arrangements between education providers in different countries permit students to gain credit for courses/programs offered and delivered by collaborating institutions. Courses can also be offered as a combination of online courses from host countries (i.e. a provider from U.S.) and online or face-to-face courses in source countries (i.e. a provider from another country). Courses taken from the provider in the source country are articulated to the provider in the host country. The student receives the degree from the provider of the host country only.

3. Virtual/Distance - Arrangements where education providers deliver courses/programs to students in different countries through distance and online modes. These may include some face-to-face support for students through domestic study or support centers. All 
courses are provided by the education provider in the host country with partner institutions providing student support services if available. The student receives the degree from the provider of the host country only.

\section{Barriers for Mode 1 Online Programs}

The literature identifies various aspects that can currently hinder the development of Mode 1 . Barriers include: legal/ regulatory factors, economic, technology, language and culture, curricular relevance, quality and reputation, and the competitive landscape.

(1) Legal/ regulatory factors - The basic governing agreements of export, including educational service export, are outlined in GATS [7] which liberalized trade for its member countries. In addition to GATS, regulations of both the education provider's host country and the student's source country where the student is located also govern the institutions providing TNE. Regulatory systems have been behind in responding to the challenges posed by Mode 1, and the regulations that do exist tend to relate more to programs established through Mode 2 [26]. While most governments cannot prohibit their residents from enrolling in online programs via Mode 1, they can require that such programs be registered or accredited locally in order for their credentials to be recognized in country, and to be able to advertise and market these programs in country. While there is no one central international accreditation body, UNESCO has developed a Portal that provides reference to accredited institutions in many countries (https://www.whed.net/home.php). Aside from accreditation, measures used by countries that may limit access include restriction of student loan eligibility, copyright regulations, and residency restrictions [5]. Other governments have worked to ease requirements. In Malaysia, students in higher education are required to complete three compulsory subjects set by the Malaysian government as part of their program of study [27]. To date, Malaysia has passed measures to exempt TNE providers from this requirement. Still, requirement and regulatory burdens like in Malaysia exist and vary from country to country. Even in the U.S., the State Authorization and Reciprocity Agreements (SARA) allows or restricts some programs to be offered from one state to another [50]. California remains a nonmember which restricts programs offered from other states and even some members of SARA maintain exceptions that identify certain programs or course offerings to be limited.

(2) Economic - Students who study abroad or through TNE are considerably more likely to come from economically and educationally advantaged backgrounds than other students [25]. This means that the majority of people in developing countries, those that are economically disadvantaged, may still not have access to higher education. Simply, they cannot afford it. This lack of access is further exacerbated by the overall reductions in national investment by countries on higher education [8], showing decreasing subsidies and scholarship availabilities [8], [14]. Also, credit instruments, consumer loans, or installment loans for education are severely deficient or even nonexistent. Thus, ability to pay by consumers and willingness to pay by governments, further limit the market for TNE. However, it could also be seen as an opportunity to expand the market if costs could be lowered. Economic barriers also include the lack of investment by nations to support infrastructure such as broadband technology as well as the cost of access to broadband connections. 
(3) Technology constraints - Advanced technologies in computers, multi-media and learning management systems (LMS), are capable of supporting audio and video functionalities, but these may be out of reach for many students due to prohibitive cost or absence of the technology. Videoconferencing that requires more bandwidth is usually not adequately available in many parts of the world. Even with emerging mobile technologies that offer connectivity to remote areas, the requirements of many online platforms may still be unattainable. In places where there is adequate availability and connectivity, the reliability and resilience of the critical infrastructure may be inadequate. These infrastructures, depending on where they are located, can be especially vulnerable to natural disasters and political instability that are quite common circumstances in many developing and emerging countries.

(4) Language and Culture - Language poses a barrier for many students who would like to study in the U.S. or Europe but have not met English language requirements or do not have a sufficient proficiency in the language to achieve success [8], [20]. A new development worth noting is the recent progress in multi-lingual technology, where those who do not speak English can increasingly access resource and online learning in their native languages [21]. Although in its infancy, the potential could be groundbreaking.

General agreement exists that TNE needs to be culturally sensitive and responsive [5]. The relative lack of body language and heavy reliance upon written words in online learning environments can present challenges to students from some cultures which rely heavily on informal or non-verbal communication [5]. Further, some researchers have expressed concerns over the westernization of education [14]. Guttman [28] adds that the nation-building role of higher education can be undermined by "a mismatch between offshore curricula and local hopes of building national cohesion, maintaining cultural identity and addressing local resource needs". This local relevance of curricula is further discussed as a barrier in the next section.

(5) Curricular Relevance- The success of global online education relies on being able to develop "curriculum that is relevant to learners wherever they happen to reside" [29]. Globalizing curriculum requires standardizing teaching to ensure that students share the same education regardless of their location [30]. This relies on removing specific references to local experiences and examples that may confuse or distract geographically distant students, as well as focusing on universal approaches that can be applied in any context. However, by trying to standardize and universalize courses runs the risk of abstracting the curriculum from real world contexts [31]. UNESCO Assistant Director-General of Education, Jacques Hallak warns- "the danger is that companies selling education outside their frontiers will attempt to impose the same standards everywhere, and this will dissociate education from the social, cultural and political origins of a country" [32].

(6) Quality and Reputation - Unlike in the U.S. where a majority of academic leaders perceive the learning outcomes in online programs as "the same or superior to those in face-to-face" [33], the perception and experience is quite different outside the U.S. Quality control measures in the U.S. for online courses are fairly robust. In contrast, Guri-Rosenbilt [4] point to the proliferation of low quality and spurious programs offered in many countries that do not have any regulations in place. Overall, the gap between quality and cost is at times so significant that TNE as a means of building developing nations can be viewed skeptically, even unfavorably [4]. This is a major 
concern within countries and a greater problem internationally. Whether real or perceived, the quality of online learning courses vary [4], [5], [21]. In Africa for example, consumers have expressed problems about the low quality and lack of accreditation of foreign TNE providers, particularly when those providers are for-profit institutions [5].

One study surveyed students from Hong Kong enrolled in an Australian TNE located in Hong Kong regarding their perception of online learning [31]. Results from the survey show that students did not positively regard fully-online programs as an alternative to face-to-face. Responses ranged from total rejection of fully-online provision to marginal support of fullyonline provision of programs. In her paper, Milizewska [31] sites Debowski [34] and Ziguras \& Rizvi [30] who agree that fully-online programs is generally perceived to be less effective than those that were face-to-face. Although this paper was done a number of years ago, the perception from past experiences may still persist.

The challenge of assuring the quality of studies by the students in an online setting is the difficulty of communicating and monitoring remotely. The broader and farther the operation of the service provider from the students the more difficult to communicate and track students. This becomes especially challenging when students are not particularly fluent in English, and where the academic cultures differ. Even with Proctor $U$ and partnering with local proctoring services, enforcing academic honestly and integrity is problematic at a distance.

(7) Competition - The online education market has become highly competitive, and universities are undergoing pressure to develop programs. The development of regional hubs for TNE make foreign higher education available regionally or locally at an affordable price [14], [15]. Many developing countries are attracting leading universities from host countries to offer their programs in-country (i.e. through Mode 3) for their local students as well as for regional students in neighboring countries [15]. Moreover, as countries increase access to higher education, universities of many source countries have emerged as strong international competitors themselves. China for example, primarily a source country a decade ago, has now emerged as a top five host country, drawing regional enrollments from its neighboring Asian countries. In addition to the rise of the regional hubs, the entry of the countries without English speaking backgrounds also adds more diversity in TNE [15].

The next section will describe how the enablers and barriers combine to date in Mode 1 Engineering Management Master's Degree Programs offered at two U.S. universities: Washington State University in Pullman, WA and Old Dominion Universities in Norfolk VA.

\section{Engineering Management Programs in the U.S.}

Engineering management (EM) is a relatively new discipline compared to the other traditional engineering disciplines and the number of EM programs has grown in response to increasing student enrollments [35], [36], [37], [38]. In the last decades, the earlier growth of EM that started in the U.S. [35] has now expanded to a large number of universities all over the world.

The ASEE Profiles of Engineering and Engineering Technology colleges [39] lists approximately $100 \mathrm{EM}$ and EM-related programs. The American Society for Engineering 
Management (ASEM) lists well over 100 EM programs in its current roster for 2018 [40]. Compared to graduate programs, there are fewer undergraduate EM programs [37],[38]. At the Master's level, the percentage of EM graduates relative to the total of engineering graduates remains constant and relatively stable. Universities in 41 states have some kind of graduate level EM program (only 9 states do not) [40]. Thus, although Engineering Management is a relatively new discipline, Engineering Management programs are clearly well established throughout the U.S. and therefore can potentially benefit from considering a Mode 1 export service.

Of the existing EM programs, most of the EM Master's programs, have already been established online. For example, the U.S. News and World Report lists 63 online EM programs [41]. Ozelkan and Galambosi [36] observed that among the twenty leading EM programs in 2009, those that offered online courses had 53\% higher enrollments and $78 \%$ more degrees conferred than those that did not. EM online programs are offered in the following formats:

1. Asynchronous: The lectures are pre-recorded and are viewed and listened to by the students at any convenient time and place. Then students are expected to take some assessment like quizzes or tests. This is the most common form for online education as it is easily implementable, and it gives faculty and students flexibility to be located from anywhere as long as they have access to the Internet. Depending on the medium of the course being offered, there may be little interaction with a professor. For example, a recorded program in CD-ROM has very limited interface between fellow students and faculty. Other asynchronous courses on online platforms may require more participation and interactions in the form of discussion forums and group work through wikis.

2. Synchronous: The lectures are in real-time, typically with live interactions through videoconferencing, chat, and/or messaging apps. Although it also has no location restriction like asynchronous, both faculty and students have to be available and connect together at specified times that the real-time live interactions take place. It mimics more closely to the traditional classroom experience except that instead of being in a physical classroom, the teacher and students meet online in a designated "course room" weekly. The students and teacher access and connect to this collaborative space to meet as a live class session. During the class session, the teacher may lecture, facilitate class discussions and/or interactive activities, assign classwork to be worked on individually or as a team, or administer a test. The activities are very similar to what can be done in a traditional classroom setting.

3. Hybrids: This is a combination of synchronous online and in-class learning. An online class shares the professor in a traditional on-campus class by broadcasting that class in the Internet. Hybrid classes increase space utilization and resources can be shared by both on-campus students as well as online students.

These online delivery formats are discussed in the next sections, in the context of two example programs: one from the west coast and one from the east coast of the United States: the Washington State University Engineering and Technology Management program originating in Pullman, Washginton and Old Dominion University Engineering Management program originating in Norfolk, Virginia.

\section{Washington State University's Engineering and Technology Management Program}


Washington State University's (WSU's) Engineering and Technology Management (ETM) program provides working engineering professionals with the knowledge, tools, and skills to manage projects, operations, organizations, finances, and people. Live, online courses (i.e. synchronous) are available and can be accessed from anywhere in the world. WSU ETM offers a Master's in Engineering and Technology Management (METM) and seven graduate certificates in constraints management, construction project management, logistics and supply chain management, manufacturing leadership, project management, six sigma quality management, and systems engineering management.

Although online classes have been offered since 1998, WSU officially launched the Global Campus in 2012 which combines the university's online-based instructional programs and offerings, and adds programs designed to bring online education to a wider audience. It currently offers 12 fully online undergraduate degrees and 9 fully online graduate Master's degrees, including METM. The METM courses are also available to graduate students from other online programs as well as traditional on-campus programs as service or elective courses. WSU Global Campus has its own student services and technical support. It also seeks to engage distance students with co- and extra-curricular events that are free and online where they can connect with peers and experts via webinar, livestreamed events, academic contests, and various activities (e.g. online book clubs) [42].

WSU in general uses all three online delivery formats. METM courses in particular are exclusively synchronous via distance learning delivered through the Internet. The courses require high-speed Internet access. If high-speed Internet is not available where students reside, many connect from their workplaces or Internet hubs. All synchronous sessions are recorded and thus students have the option of viewing (or reviewing) the recorded sessions any time. Course materials, recorded lectures, assignments, tests, and/or other assessments are all managed in course sites that are available on the Internet and can be accessed by students wherever they may be. Also, many of its faculty reside in different parts of the U.S and can teach from wherever they are. WSU uses the Blackboard Learning Management System (LMS) and Blackboard Collaborate Ultra as its online platform and videoconferencing application.

Of the 3,086 Global Campus students, 141 are international students (i.e. Mode 1) who are located in 45 different countries [43]. 4 ( 3\% of Mode 1) are students in the METM program. Additionally, a number of students enrolled in METM courses are students from other non-ETM programs who take the courses as electives. Examples of the countries where Mode 1 students reside are Sudan, Canada, Mexico, Bermuda, Turks and Caicos, Qatar, Puerto Rico, and Sweden.

\section{Old Dominion University's Engineering Management Program}

The Engineering Management and Systems Engineering (EMSE) Department at Old Dominion University (ODU) offers a Master of Engineering Management (MEM), Engineering Management certificate, and an Engineering Management minor option for its Bachelor programs in engineering. The MEM program is directed at working professionals as well as traditional full-time students seeking technical graduate degrees. The engineering management minor and certificate programs allow students to supplement their more traditional engineering degrees with management and project-based decision making tools. 
Program mobility at ODU uses all three delivery formats with a wide range of online graduate programs offered in the Master's level (29 fully online Master's degrees). Unlike WSU, the courses for both the EM graduate and undergraduate degrees and the certificate are available on campus in a traditional classroom setting as well as via distance learning (i.e. Mode 1). Courses could be attended live on the Norfolk main campus, from the ODUs satellite campuses located in Virginia, online, or CD-rom. Distance learning at EMSE are synchronous, asynchronous, or hybrid depending on how the course is offered. Undergraduate courses are not offered asynchronously [44].

ODU uses the Blackboard LMS and Webex as its online platform and videoconferencing application respectively. ODU online programs evaluate the applicant's status and ability to take online courses with a pre-application survey which helps to determine the applicant's suitability for online courses. Major support services for Mode 1 students are provided by the Office of International Programs and Office of Distance Learning. Mode 1 students are directly supported by the Director of ODUOnline International.

63 students are Mode 1 students with one ( 1\%) student taking EM courses. Though not counted as Mode 1, it is worth noting that many students taking courses while abroad are U.S. nationals deployed by the military and living in various countries such as Japan.

\section{Enablers at WSU and ODU}

The leading driver for offering courses via Mode 1 for both WSU and ODU is ease in market entry. There are no additional costs incurred as the courses are already developed and available across all states in the U.S. The value proposition is that opening these courses to a worldwide audience increases the numbers of students with no requirement for physical classrooms outside of the technology required to access the online platform. Thus, the expectation is that whatever market demand is out there for EM, is captured by merely opening access to students abroad (Mode 1). This is not unlike many EM online programs where the strategy is an extension of the "build it and they will come" motto, where the existing program is migrated to an online platform, and then extended locally, regionally, nationally, and internationally, sometimes all at once. For WSU and ODU, providing access to students abroad means admission and entry through the university website and connecting to the university's LMS platform via the Internet to access and/or attend classes. International students can learn about WSU's distance course and submit applications through its WSU Global Campus webpage (https://globalcampus.wsu.edu). Though named "Global Campus", the website caters to any student outside of its traditional campus. Similarly, ODU has the ODU Online webpage (https://online.odu.edu). In addition, ODU has a webpage dedicated to information targeted specifically for Mode 1 students (https://online.odu.edu/international).

It has been observed that most students in both synchronous and asynchronous formats, including Mode 1 students, exhibit proficiency with the online technologies and express an inclination with the online environment over a traditional classroom, further underscoring the online culture prevalent of the times. Moreover, the same as any online student, Mode 1 students benefit from the flexibility of the online format that is compatible with work-related 
requirements, especially those who travel for work, and family obligations. This further highlights the advantages of the online preference over campus life. End of program surveys in WSU show $>90 \%$ satisfaction with the fully online format with positive comments specifically directed to the preference for the online nature of the program. The benefits of internationalization have been observed in the classroom experience of conducting classes with a diverse student body sharing varied perspectives in a global context. Both programs have no current partnerships with other international universities to offer EM programs abroad. However, faculty who are previous residents of countries abroad or have contacts with foreign colleagues have expressed interest in making connections to facilitate EM program collaborations with other international institutions. This has some potential to enable partnerships to offer the EM programs in foreign countries.

\section{Barriers at WSU and ODU}

Ability to pay by students abroad, especially from developing countries, has been the topmost known barrier. Both universities charge out-of-state tuition for foreign students. WSU charges $\$ 1,375$ per credit and ODU charges $\$ 568$ per credit [45], [46]. This is more costly (up to 10X more) compared to local institutions in developing countries (e.g. Ateneo, a private university in the Philippines charges less than $\$ 100$ per credit [47]). Striving to address this, ODU is currently offering international scholarships for Mode 1 students [48].

Legal and regulatory barriers abroad are not explicitly known by most educational providers and there is no formal process to identify or address them. ODU and WSU for example, rely on the students to ensure that they are not in violation of their own country's restrictions. Thus, only students whose country residence have free markets to education can feasibly and practically enroll, while access to those countries that do not recognize U.S. qualifications remains out of reach. Interestingly, both institutions have expressed discouragement from certain U.S. States that have similar restrictions to access (e.g. by not being a member of SARA). Both Virginia and Washington are members of SARA and can deliver distance education to students in any SARA states but may not be authorized to deliver to non-member states.

Language continuous to be a barrier. This is evident in the experience of both institutions with English as a second language (ESL) students. ODU requires TOEFL and GRE language proficiency in its MEM program admissions to screen English-deficiency. While WSU does not require English proficiency tests, there are support services available such as the Graduate Professional Writing Center to help all online students at WSU including Mode 1 students.

An operational barrier identified was the time component of synchronous courses. Synchronous courses have a set time for student to attend live classes with instructors. So corresponding times may be the middle of the night or really early in the morning for students abroad. To get around this, recordings of the live sessions are available to students for viewing at any time. Connection issues are also addressed by allowing downloadable versions of the recordings. Acquiring textbooks and/or software applications for the courses has also been an issue. Print copies take time to be delivered to other countries by mail. Downloadable digital versions of textbooks and applications are faster to get and more convenient. However, embargoes such as the US embargo 
with Sudan [49] for example have imposed an extra challenge to acquiring academic resource requirements that require financial transactions.

Like many universities, academic integrity is a serious institutional cornerstone at both institutions, as it is directly related to academic rigor and quality. Operationally, securing examinations and verifying identity is the topmost concern. ODU and WSU both subscribe to programs like ProctorU, which provides electronic proctoring. ODU also relies on local libraries and universities for physical exam proctoring if available in the foreign country. Various assessments at WSU and ODU are not proctored such as take home exams, case studies, and/or projects. These alternative assessments tend to be highly individualized original inquiry, exploration of knowledge, and investigation of problems. Plagiarism is checked through applications such as Self Assign or iThenticate.

Another barrier met is the perception that online courses are not as rigorous as face-to-face courses. As stated previously, past experience from low quality programs, mostly for-profit, have plagued online education abroad. This is a significant hurdle for many US programs now seeking to offer their own online programs, especially those with less name recall. What many U.S. institutions are counting on is the overall recognition of the unparalleled quality of the U.S. higher education system, in whatever shape, form, or mode it is offered.

\section{Conclusion}

This paper reviewed enablers and barriers for Engineering Management Degree Granting Programs offered online by universities located in the U.S. to students located in foreign countries. This situation is a subset of TNE, specifically Mode 1 service exports as defined by the World Trade Organization. The paper described categories of enablers and barriers for such programs summarized in Table 3.

Table 3

SUMMARY OF ENABLERS AND B ARRIERS FOR MODE 1

\begin{tabular}{|c|c|}
\hline Enablers & Barriers \\
\hline $\begin{array}{l}\text { 1. Market Potential in countries that } \\
\text { cannot supply desired EM courses } \\
\text { 2. Ease of Market Entry by exporting } \\
\text { existing courses } \\
\text { 3. Student/ Consumer Preference } \\
\text { - Avoids culture shock and } \\
\text { loneliness } \\
\text { - Allows students to maintain } \\
\text { current jobs in home countries } \\
\text { 4. Current Online Culture } \\
\text { 5. Internationalization } \\
\text { 6. Addresses current visa and } \\
\text { immigration issues- }\end{array}$ & $\begin{array}{l}\text { 1. Potential limitations on the } \\
\text { recognition of qualification in } \\
\text { student's home country } \\
\text { 2. Inability of potential students (and } \\
\text { students' countries) to obtain required } \\
\text { financial support for education } \\
\text { 3. Unavailability of required technology } \\
\text { in student's home country even if } \\
\text { student could afford it } \\
\text { 4. Language and cultural barriers } \\
\text { 5. Curriculum may not be relevant or } \\
\text { appropriate to learners wherever they } \\
\text { reside } \\
\text { 6. Quality and existing reputation of } \\
\text { Online education }\end{array}$ \\
\hline
\end{tabular}




\begin{tabular}{|c|c|c|}
\hline 7. & $\begin{array}{l}\text { Copes with restricted mobility } \\
\text { policies as visa is not required for } \\
\text { students staying in home country } \\
\text { - Helps to limit brain drain for } \\
\text { source countries } \\
\text { Potential for collaboration with } \\
\text { institution in the student's country }\end{array}$ & 7. Competition \\
\hline
\end{tabular}

Current trends comparing specifically cross-border supply of education (Mode 1) and consumption of education abroad (Mode 2) indicate a plateau or slowing of Mode 2 export services and a growth in Mode 1 export services for the U.S.. The U.K.'s nearly three times proportion of overall export services in Mode 1 as compared to the U.S. further demonstrates the feasibility of a growing opportunity for Mode 1 export services in the U.S.. Universities with online programs, including Engineering Management Degree Granting Programs, are well advised to focus on leveraging enablers and minimizing barriers to Mode 1 export service. Using the Mode 1 Engineering Management Master's Degree Programs offered by two U.S. institutions: Washington State University in Pullman, Washington and Old Dominion University in Norfolk, Virginia as example cases, several additional suggestions emerge:

- develop a dedicated international webpage specifically targeted to Mode 1 students;

- embrace students from anywhere in the world putting in place policies to deal with political unrest, world climate, and additional factors which can otherwise impact student success;

- consider collaborating with other international universities so that EM programs can be offered abroad but through local channels;

- offer international scholarships or leverage existing international student funding programs;

- provide formal support for English as a second language students;

- consider synchronous and asynchronous delivery the perspective of the international student;

- investigate legal and regulatory barriers abroad to address these potential barriers; and emphasize university reputation and faculty expertise in delivering high quality online education.

How enablers and barriers combine to determine the viability of Mode 1 Engineering Management Programs is a function of the students, the host countries, the offering institutions and the competitive climate at any time. While the two Engineering Management example programs currently involve a very small number of international engineering managmenet students, their existence suggests that the enablers and barriers for exporting online engineering management programs may align in a manner that could permit growth of this product with resulting benefits to the universities offering such programs and the students taking the programs. 


\section{References}

[1] UNESCO Institute of Statistics, "UIS Statistics", data.uis.unesco.org, 2018. [Online]. Available: http://data.uis.unesco.org. [Accessed: Dec. 12, 2018].

[2] OECD, Benchmarking higher education system performance: Conceptual framework and data, Enhancing Higher Education System Performance. Paris: OECD, 2017.

[3] Council of Europe, "Code of Good Practice in the Provision of Transnational Education", coe.int, 2001. [Online]. Available: https://www.coe.int/t/dg4/highereducation/recognition/Code\%20of\%20good\%20practice_E N.asp. [Accessed: December 14, 2018].

[4] S. Guri-Rosenblit, "Open/distance teaching universities worldwide: Current challenges and future prospects", EudAkcja Magazyn, vol. 2, no. 4, pp. 4-12, 2012.

[5] B. Bannier, "Global Trends in Transnational Education", International Journal of Information and Education Technology, vol. 6, no. 1, pp. 80-84, 2016. Available: 10.7763/ijiet.2016.v6.663. [Accessed: December 2, 2018].

[6] R. Merola, "What Does Data Tell Us about Cross-border Online Learning?", International Higher Education, no. 89, p. 21, 2017. Available: 10.6017/ihe.2017.89.9842

http://dx.doi/org/10.6017/ihe.2017.89.9768. [Accessed: December 2, 2018].

[7] World Trade Organization, General agreement on trade services. Geneva: WTO, 1994. Available: https://www.wto.org/english/docs_e/legal_e/26-gats.pdf. [Accessed: December 2, 2018].

[8] Institute of International Education, A world on the move: trends in global student mobility, Issue 2. New York: Institute of International Education, March 2018. Available: https://www.iie.org/Research-and-Insights/Project-Atlas. [Accessed: December 2, 2018].

[9] Export.gov, "Education and Training Services Resource Guide 2018", export.gov, 2018. [Online]. Available: https://2016.export.gov/industry/education/eg_main_108888.asp. [Accessed: December 2, 2018].

[10] Institute of International Education, Open Doors: Report on International Educational Exchange. NY: Institute of International Education, 2018. Available: https://www.iie.org/Research-and-Insights/Open-Doors/Open-Doors-2018-MediaInformation._[Accessed: December 1, 2018].

[11] R. Garrett, "Whatever happened to the promise of online learning? The state of global online higher education", http://www.obhe.ac.uk, 2017. [Online]. Available: http://www.obhe.ac.uk/documents/view_details?id=1091. [Accessed: December 1, 2018]. 
[12] J. Seaman, E. Allen and J. Seaman, "Grade increase: tracking distance education in the United States", Babson Survey Research Group, Babson Park, 2018. Available: http://www.onlinelearningsurvey.com/highered.html. [Accessed: December 1, 2018].

[13] J. Knight, Borderless, offshore, transnational and cross-border education: definition and data dilemmas. London: The Observatory on Borderless Higher Education, 2005.

[14] F. Alam, Q. Alam, H. Chowdhury and T. Steiner, "Transnational Education: Benefits, Threats and Challenges", Procedia Engineering, vol. 56, pp. 870-874, 2013. Available: 10.1016/j.proeng.2013.03.209. [Accessed: December 1, 2018].

[15] P. Chen, "Transnational Education: Trend, Modes of Practices and Development", International Journal of Information and Education Technology, vol. 5, no. 8, pp. 634-637, 2015. Available: 10.7763/ijiet.2015.v5.582. [Accessed: December 21, 2018].

[16] P. Altbach and J. Knight, "The Internationalization of Higher Education: Motivations and Realities", Journal of Studies in International Education, vol. 11, no. 3-4, pp. 290-305, 2007. Available: 10.1177/1028315307303542. [Accessed: December 3, 2018].

[17] P. Altbach and H. De Wit, "Trump and the Coming Revolution in Higher Education Internationalization", International Higher Education, no. 89, p. 3, 2017. Available: 10.6017/ihe.2017.89.9831. [Accessed: December 3, 2018].

[18] H. Ward, Internationalization in action. Washington DC: American Council on Education, 2016.

[19] D. Deming, et al., "Can Online Learning Bend the Higher Education Cost Curve?", American Economic Review, Papers \& Proceedings, 105 (5):496-501, 2015.

[20] M. Fischbacher-Smith, et al., "Supporting Student Transition from Glasgow International College", in University of Glasgow 8th Annual Learning \& Teaching Conference, Glasgow, 2015.

[21] R. Liang and D. Chen, "Online Learning: Trends, Potential and Challenges", Creative Education, vol. 03, no. 08, pp. 1332-1335, 2012. Available: 10.4236/ce.2012.38195. [Accessed: December 3, 2018].

[22] N. Varghese, "GATS and Transnational Mobility in Higher Education", in Higher Education on the Move: New Developments in Global Mobility, R. Bhandari and S. Laughlin, Ed. New York: AIFS Foundation, 2009.

[23] Canada Bureau of International Education (CBIE), From Permits to Permanency: Supporting the International Student in Status Transition. Ottawa: CBIE, 2016. Available: https://cbie.ca/wp-content/uploads/2016/07/Immigration-RiB.pdf. [Accessed: January 2, 2019]. 
[24] The Expert Council of German Foundations on Integration and Migration, Train and Retain Career Support for International Students in Canada, Germany, the Netherlands and Sweden. Berlin: The Expert Council of German Foundations on Integration and Migration. Available: https://www.svr-migration.de/wp-content/uploads/2015/08/Study_Train-andRetain_SVR-research-unit_WEB.pdf._[Accessed: January 2, 2019].

[25] G. Rhoades, "Backlash Against "Others"", International Higher Education, no. 89, p. 2, 2017. Available: 10.6017/ihe.2017.89.9830. [Accessed: December 1, 2018].

[26] APEC, "Asia-Pacific Economic Cooperation", www.apec.org, 2001. [Online]. Available: https://www.apec.org/Meeting-Papers/Leaders-Declarations/2001/2001_aelm. [Accessed: January 2, 2019].

[27] G. McBurnie and C. Ziguras, "The regulation of transnational higher education in Southeast Asia: Case studies of Hong Kong, Malaysia and Australia", Higher Education, vol. 42, no. 1, pp. 85-105, 2001. Available: 10.1023/a:1017572119543. [Accessed: January 2, 2019].

[28] C. Guttman, "Offshore threats", The UNESCO Courier: 35, 2000.

[29] A. Bates and J. Escamilla de los Santos, "Crossing boundaries: making global distance education a reality.", Journal of Distance Education, vol. 12, p. 49, 1997.

[30] C. Ziguras and F. Rizvi, "Future directions in international online education", in Transnational Education: Australia Online, D. Davis and D. Meares, Ed. Sydney: IDP Education Australia, 2001, pp. 151-164.

[31] I. Miliszewska, "Is It Fully "On" or Partly "Off"? The Case of Fully-Online Provision of Transnational Education", Journal of Information Technology Education, vol. 6, pp. 499514, 2007.

[32] B. James, "Does profit put culture at risk?", International Herald Tribune, pp. 17-19, 2000.

[33] E. Allen, J. Seaman, "Changing Course: Ten Years of Tracking Online Education in the United States". Babson Survey Research Group and Quahog Research Group, Babson Park, 2013.

[34] S. Debowski, "Lost in internationalised space: The challenge of sustaining academics teaching offshore", in 17th IDP Australian International Education Conference, Securing the future for international education, IDP, 2003.

[35] C. lo Storto, "Engineering management education: trends, concerns, and open questions", 2008 IEEE International Engineering Management Conference, pp. 1-4, 2008. Available: 10.1109/iemce.2008.4618030. [Accessed: December 13, 2018].

[36] E. Ozelkan and A. Galambosi, "Value of online curriculum for engineering and engineering management program", in American Society for Engineering Education, Austin, 2009. 
[37] K. Abel and A. Ganguly, "A comparative inventory of core courses in select graduate EM programs", in ASEE Annual Conference \& Exposition, Louisville, 2010.

[38] W. Daughton, "Trends in Engineering Management Education From 20112015", Engineering Management Journal, vol. 29, no. 1, pp. 55-58, 2017. Available: 10.1080/10429247.2017.1280747. [Accessed: December 13, 2018].

[39] American Society for Engineering Education (ASEE), "ASEE Profiles of Engineering and Engineering Technology Colleges (2017),", ASEE, 2017. Available: https://www.asee.org/papers-and-publications/publications/college-profiles. [Accessed: December 13, 2018].

[40] American Society for Engineering Management, "Engineering Management Program Directory", www.asem.org, 2017. [Online]. Available: https://www.asem.org/EM-ProgramList. [Accessed: December 13, 2018].

[41] US News and World Report, "Online Engineering Management Master's Degree", www.usnews.com, 2018. [Online]. Available: https://www.usnews.com/education/online-education/engineering-management-mastersdegree. [Accessed: December 13, 2018].

[42] Washington State University, "Global Campus", globalcampus.wsu.edu. [Online]. Available: https://globalcampus.wsu.edu. [Accessed: January 11, 2019].

[43] Washington State University, "WSU Enrollment Headcount by Campus, Level Minority, Full-time/Part-time, Sex and International Totals and Percentages", www.wsu.edu, 2018 [Online]. Available: https://ir.wsu.edu/documents/2018/12/enrollment-headcount-bycampus-level-and-all-campus-total-fall-2018.pdf/. [Accessed: January 11, 2019].

[44] Old Dominion University, "Engineering Management and Systems Engineering", odu.edu. [Online]. Available: https://www.odu.edu/emse. [Accessed: January 11, 2019].

[45] Old Dominion University, "ODU EM Tuition", odu.edu. [Online]. Available: https://www.odu.edu/tuition-aid/costs-tuition/tuition/tuition-rates. [Accessed: January 11, 2019].

[46]. Washington State University, "Tuition and Finances", etm.wsu.edu. [Online]. Available: https://etm.wsu.edu/tuition/. [Accessed: January 11, 2019].

[47] Ateneo, "Graduate level tuition and fees", ateneo.edu. [Online]. Available: Ateneo de Manila, http://www.ateneo.edu/ls/graduate/graduate-level-tuition-and-fees. [Accessed: January 11, 2019].

[48] Old Dominion University, "International Student Scholarship", online.odu.edu. [Online]. Available: https://online.odu.edu/cost/international-student-scholarship. [Accessed: January $11,2019]$. 
[49] US Department of the Treasury, "Sanctions Programs and Country Information", treasury.gov. [Online]. Available: https://www.treasury.gov/resourcecenter/sanctions/Programs/Pages/Programs.aspx. [Accessed: January 15, 2019].

[50] US Department of Education, "State Authorization and Reciprocity Agreements (SARA)", ww2.ed.gov. [Online]. Available:

https://www2.ed.gov/policy/highered/reg/hearulemaking/2012/pii-ncsara-infosheet.pdf. [Accessed: January 30, 2019]. 